\title{
Cuando la cleptocracia no alcanza: los delitos contra las empresas
}

\section{When kleptocracy is not enough: crimes against businesses}

\author{
Carlos Javier Vilalta-Perdomo*
}

\begin{abstract}
How many crimes are committed against businesses and what is the economic damage they cause? This study answers the previous question and includes a preliminary spatial and correlation analysis that allows explore the extent, severity, location and the effects of this public security problem. Based on two victimization surveys against businesses, it is found that direct economic losses and expenditures on protection devices against crime reach multimillion figures. A geography of economic losses and of expenditure on protection devices against crime measures were also found.
\end{abstract}

Keywords: crime, victimization, business, survey, Mexico.

\section{Resumen}

¿Cuántos delitos contra las empresas se cometen y cuál es el daño económico que producen? Con este estudio se responde esta pregunta, y se agrega un análisis inicial estadístico de diversas características elementales de este problema de seguridad pública. Con base en las encuestas de victimización contra las empresas de 2011 y 2013 en México realizado por el Instituto Nacional de Estadística y Geografía (Inegi), se encontró, principalmente, que las pérdidas económicas directas y los gastos destinados en medidas de protección contra el delito son multimillonarias. Otro problema claramente identificable es la alta victimización empresarial por actos de corrupción, en donde los victimarios son funcionarios de gobierno.

Palabras clave: delito, victimización, empresa, encuestas, México. 


\section{Introducción}

La lucha contra el crimen organizado y los cárteles de las drogas no es la única problemática ni la mayor amenaza en materia de seguridad para la población mexicana. Para la mayoría de los ciudadanos, el crimen en sus formas más comunes como el robo en la calle o el transporte público, la extorsión telefónica, los actos de corrupción, etcétera, son los que más afectaciones provocan. Pero la percepción del problema de la inseguridad es peor aún a los hechos delictivos. En 2014, 45\% de la población adulta en el país reportó sentirse insegura en su colonia o localidad de residencia, y 64\% dijo sentirse igual en su municipio, según datos de la Encuesta Nacional de Victimización y Percepción sobre Seguridad Pública (Inegi/ Envipe, 2014). Esta percepción modifica nuestros comportamientos y afecta nuestra calidad de vida. Ese mismo año, 69\% de los hogares con hijos reportaron haber dejado de dar permiso a sus hijos menores para salir a la calle por miedo al crimen, y 53\% evitaron salir de noche por el mismo motivo (Inegi/Envipe, 2014a). Vivir con miedo es vivir en sumisión. Y la mayoría de la población en este país vive con miedo.

Pero las empresas también operan con riesgos y miedo, ${ }^{1} \mathrm{y}$ de esto no se habla mucho. Con base en la Encuesta Nacional de Victimación de las Empresas (ENVE) (Inegi/ENVE, 2014), ${ }^{2}$ sabemos que 33.6\% de las empresas (o 336.3 unidades económicas por cada mil) establecidas en México y que operan dentro de la formalidad, fueron víctimas de al menos un delito en 2013 (cuadro 1). En términos absolutos, ese año se cometieron dos millones 500 mil delitos contra un millón 200 mil empresas; de un total de tres millones 700 mil empresas en el país. Esto da un promedio de dos delitos por empresa. ${ }^{3} \mathrm{Y}$ si bien, la victimización contra las empresas se redujo significativamente entre 2011 y $2013,{ }^{4}$ a diferencia de lo sucedido contra los hogares en donde aumentaron los delitos y las víctimas, en una comparación internacional frente a otros 20 países de la Unión Europea, las empresas mexicanas se hallan a media tabla en términos de sus niveles de victimización, aunque ligeramente por encima de la media europea. Más empresas son victimizadas por el delito en otros países, pero el nivel de victimización entre las empresas mexicanas no es comparativamente menor.

${ }^{1}$ Una tipología de los tipos de victimización contra las empresas se presenta en Vilalta (2017).

${ }^{2}$ Es importante anotar que esta fuente de información es oficial y consiste en una muestra probabilística representativa de empresas mexicanas en el territorio nacional; la representatividad de esta información en el ámbito estatal permite hacer comparaciones e inferencias entre entidades federativas cada ańo del levantamiento. Para el tipo de análisis correlacional descriptivo que se realiza en este estudio, esta fuente es apropiada y suficiente.

${ }^{3} \mathrm{Al}$ cociente del número de delitos por víctima se le llama tasa de concentración delictiva.

${ }^{4}$ A razón principalmente de un descenso abrupto en el reporte de actos de corrupción. 


\section{Cuadro 1 \\ Prevalencia en los delitos \\ contra las empresas, 2011 y 2013}

\begin{tabular}{lccc}
\hline & Empresas & Victimas & Tasa $^{*}$ \\
\hline 2011 & $3,717,291$ & $1,389,000$ & 373.7 \\
2013 & $3,793,806$ & $1,276,018$ & 336.3 \\
Cambio & $2.1 \%$ & $-8.1 \%$ & -37.4 \\
\hline
\end{tabular}

Fuentes: cálculos propios con base en la Encuesta Nacional de Victimización de Empresas, Inegi/ ENVE, 2012 y 2014. *Las tasas se presentan por cada mil unidades económicas.

Los daños económicos del delito en el sector productivo son muy considerables. En 2013, las pérdidas económicas directas ascendieron a 54 billones de pesos, ${ }^{5}$ es decir, un dańo económico promedio de 42,000 pesos por empresa. Ante esta crisis de seguridad, las empresas han reaccionado protegiéndose, en 2013, cuatro de cada 10 tomaron alguna medida que garantizara su seguridad; principalmente instalaron cerraduras y candados, cambiaron puertas o ventanas en sus establecimientos o instalaron alarmas o videocámaras de vigilancia, pero proveerse de estas medidas implicó un alto costo que ascendió a 43 billones de pesos, o 26,000 pesos por empresa en promedio. Nótese que la suma del daño económico promedio y los gastos de protección promedio llevan a un total de 68,000 pesos promedio por empresa; todo este gasto es consecuencia del delito.

En 2011 y 2013, los delitos que más sufrieron las empresas fueron los robos de bienes o dinero, los actos de corrupción, las extorsiones y el robo hormiga (en ese orden). Estos cuatro delitos equivalen a $72 \%$ del total de los seis millones 800 mil delitos sufridos por las empresas sólo esos dos años. Un problema inicialmente detectable es que las medidas de protección mencionadas en el párrafo anterior no los pueden proteger ni de los actos de corrupción ni de la mayor parte de las extorsiones. Y otro problema identificable y preocupante son los actos de corrupción, en donde los victimarios son los funcionarios de gobierno. En 2011 y 2013, los empresarios reportaron un millón 300 mil actos de corrupción contra ellos (cuadro 2). De ahí el uso del término "Cleptocracia" en el título de este estudio.

Por todas las razones anteriores, éste es un estudio inicial que explica, cuantifica y correlaciona en el ámbito estatal, ${ }^{6}$ los diferentes tipos de pérdidas económicas y gastos en protección que la actividad delictiva, en

\footnotetext{
${ }^{5}$ Billones americanos, es decir, miles de millones.

${ }^{6} \mathrm{El}$ análisis estadístico tradicional se realiza con el paquete SPSS versión 16.0 y el análisis estadístico espacial con el paquete Geoda versión 1.6.7. Este paquete es de uso gratuito y se puede descargar en la siguiente página de internet: http://geodacenter.github.io/download.html
} 


\section{Cuadro 2 \\ Incidencia delictiva contra las empresas por tipo de delito, 2011 y 2013}

\begin{tabular}{lrrrc}
\hline & 2011 & 2013 & $\begin{array}{c}\text { Cambio } \\
\text { abs. }\end{array}$ & $\begin{array}{c}\text { Cambio } \\
\%\end{array}$ \\
\hline Total & $4,324,529$ & $2,520,584$ & $-1,803,945$ & -41.7 \\
Robo/asalto de bienes o dinero & 978,517 & 581,701 & $-396,816$ & -40.6 \\
Extorsión & 628,912 & 412,538 & $-216,374$ & -34.4 \\
Fraude & 369,575 & 274,803 & $-94,772$ & -25.6 \\
Robo de mercancía en tránsito & 254,861 & 203,388 & $-51,473$ & -20.2 \\
Robo de accesorios de vehículo & 254,186 & 168,029 & $-86,157$ & -33.9 \\
Dańos a instalaciones, maquinaria o & 138,233 & 43,534 & $-94,699$ & -68.5 \\
equipo & & & & \\
Robo total de vehículo & 78,645 & 58,440 & $-20,206$ & -25.7 \\
Actos de corrupción* & $1,066,374$ & 284,015 & $-782,359$ & -73.4 \\
Robo hormiga & 515,957 & 454,722 & $-61,235$ & -11.9 \\
Otros delitos & 39,269 & 39,415 & 146 & 0.4 \\
\hline
\end{tabular}

Fuente: cálculos propios con base en la Encuesta Nacional de Victimización de Empresas (Inegi/ ENVE, 2012 y 2014). *Este descenso abrupto y estadísticamente anómalo en los reportes de actos de corrupción merece análisis aparte en cuanto a que no se sabe si es, precisamente, un artefacto estadístico. Los resultados de la encuesta del 2016, permitirá argumentar lo anterior.

general, provoca en las empresas mexicanas. La importancia es obvia. Pero vale la pena mencionar los motivos más simples por los que la cuantificación de las pérdidas económicas es necesaria para el análisis de la victimización contra las empresas. Un motivo básico es que muchas decisiones empresariales, particularmente en las corporaciones medianas y grandes, dependen precisamente de una cuantificación de los riesgos en las operaciones, en donde son precisamente las pérdidas económicas provocadas por el delito, en sus diferentes modalidades, un componente clave de la estimación del riesgo. Otro motivo es que esta cuantificación es, o debería ser, de la mayor utilidad para las autoridades encargadas de la seguridad y la justicia, simplemente porque estas estimaciones pueden ser utilizadas para la priorización y la planeación del gasto e inversión en el sector de la seguridad y la justicia (Brand y Price, 2000).

Como se verá en este artículo, hay una marcada geografía estatal de la pérdida económica a causa del delito; las pérdidas y gastos no son en absoluto las mismas para las empresas en todos los estados. Algunos cuentan con mejores condiciones de seguridad para su desarrollo, sobre 
la base de contar con niveles notablemente menores de pérdidas económicas y gastos en protección provocadas por la actividad delincuencial.

\section{La magnitud de las pérdidas económicas y su relación con los gastos en protección}

En esta sección se ofrece un detallado análisis de las pérdidas y los gastos que ha implicado la prevención del delito. En la estadística nacional, los daños y perjuicios ocasionados por el delito contra las empresas se clasifican en cinco tipos: daños no económicos, pérdidas económicas directas, pérdidas por la suspensión o cancelación de acciones del negocio, gastos en protección contra el delito y pérdidas por las afectaciones del comercio informal (figura 1). Solamente los cuatro últimos son cuantificables monetariamente y son notablemente variables entre éstos. Lo que justifica la necesidad de realizar descripciones separadas de cada uno.

El primer hallazgo principal en esta sección es que el daño que produce la delincuencia contra el sector productivo es mucho mayor y más gravoso de lo que se puede imaginar en primera instancia. Además de las enormes pérdidas económicas directas que produce la actividad criminal (por los robos o los gastos médicos por lesiones contra los empleados), las cuales ascendieron a 65 mil millones de pesos sólo en 2011, y 54 mil

Figura 1

Los diferentes tipos de daños y perjuicios por los delitos contra las empresas

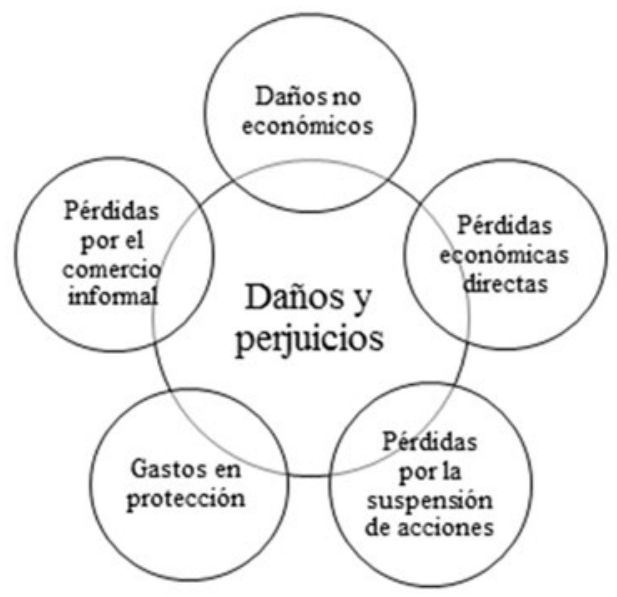

Fuente: elaboración propia con base en la conceptualización de la ENVE (Ineg/ENVE, 2012). 
millones, en $2013 ;^{7}$ también se tienen los costos derivados de acciones dirigidas a protegerse del delito, es decir, medidas de prevención situacional y de fortificación de los establecimientos, ${ }^{8}$ los cuales ascendieron a 45 mil millones de pesos en 2011, y 43 mil millones, en 2013 (cuadro 3). Esto es, en un día como cualquier otro de 2013, el sector empresarial perdía o gastaba en protegerse contra el delito alrededor de 266 millones de pesos. ${ }^{9}$

En el cuadro se muestran los valores nominales y reales, siendo estos últimos los que llevan un ajuste de precios. ${ }^{10}$ En valores reales, las pérdidas económicas directas se redujeron un total de 17\% entre 2011 y 2013. A la vez, los gastos que las empresas destinaron a medidas de protección se redujeron casi $6 \%$. La relación pérdida económica y gasto en protección también se modificó entre 2011 y 2013. En 2011, había una relación de 1.4 pesos (en valores reales) de pérdida económica directa del delito por un peso gastado en protección contra el delito, mientras que esa relación se redujo a 1.2 pesos en 2013. Es decir, la reducción de pérdidas ocasionadas por el delito en el bienio fue superior a la reducción de gastos en protección.

El segundo hallazgo es que con la reducción en los niveles de victimización entre 2011 y 2013, las pérdidas económicas totales y en promedio también se redujeron notoriamente. Teóricamente, el total de las pérdidas económicas puede cambiar de forma, independiente al promedio o pérdida por empresa victimizada; pero esto no fue así en este bienio: menos empresas victimizadas llevó, obviamente, a menores pérdidas económicas en total, pero también a una reducción en el promedio de pérdidas económicas por empresa victimizada. Nótese que las pérdidas económicas empresariales a razón de la victimización delictiva pueden ser puramente económicas, o bien producirse por una pérdida en la producción o venta de bienes o servicios del establecimiento, o por daños físicos contra el personal del establecimiento. ${ }^{11}$

La variación geográfica de la victimización es notable en términos de prevalencia y muy variable en términos de pérdidas económicas (cuadro 4).

\footnotetext{
${ }^{7}$ En valores reales de 2010.

${ }^{8}$ Por ejemplo, cambiando o colocando cerraduras, candados, puertas o ventanas, o bien instalando alarmas o videocámaras de vigilancia en los establecimientos.

${ }^{9}$ Pesos en valores reales de 2010.

${ }^{10} \mathrm{El}$ ajuste de precios se realizó dividiendo el valor nominal en cada rubro entre el índice de precios respectivo a diciembre de cada ańo con base en el índice de precios base de diciembre de 2010. La fuente de información del índice de precios es el Inegi (2012y 2014).

${ }^{11}$ Naturalmente existe la opción de contestar "otro" tipo de daño, o bien "ningún” daño. Las dos preguntas relativas en el cuestionario son las siguientes: “¿Cuánto le representó en términos económicos al establecimiento las pérdidas económicas a consecuencia del (DELITO)?” y "Dentro del rango que menciona ¿podría decirme cuál fue la cantidad aproximada que representaron las pérdidas económicas a consecuencia del (DELITO)?”.
} 


\section{Cuadro 3}

Pérdidas y gastos cuantificables totales y promedio del delito contra la empresa, 2011 y 2013

\begin{tabular}{|c|c|c|c|}
\hline & Valor nominal & Valor real ${ }^{*}$ & Promedio** \\
\hline & \multicolumn{3}{|c|}{ 2011: } \\
\hline $\begin{array}{l}\text { Pérdidas económi- } \\
\text { cas directas }\end{array}$ & $67,506,264,758.00$ & $65,109,792,359.00$ & $46,875.26$ \\
\hline $\begin{array}{l}\text { Pérdidas por la sus- } \\
\text { pensión de acciones }\end{array}$ & $62,864,183,851.00$ & $60,632,505,324.00$ & $142,410.65$ \\
\hline $\begin{array}{l}\text { Gastos en medidas } \\
\text { de protección }\end{array}$ & $47,655,581,712.00$ & $45,963,808,561.00$ & $28,956.55$ \\
\hline $\begin{array}{l}\text { Pérdidas por el co- } \\
\text { mercio informal }\end{array}$ & $39,042,948,809.00$ & $37,656,924,126.00$ & $27,110.79$ \\
\hline \multirow[t]{2}{*}{ Total } & $217,068,979,130.00$ & $209,363,030,371.00$ & - \\
\hline & \multicolumn{3}{|c|}{ 2013: } \\
\hline $\begin{array}{l}\text { Pérdidas económi- } \\
\text { cas directas }\end{array}$ & $61,093,059,174.00$ & $54,067,357,369.00$ & $42,372.31$ \\
\hline $\begin{array}{l}\text { Pérdidas por la sus- } \\
\text { pensión de acciones }\end{array}$ & n.d. & n.d. & n.d. \\
\hline $\begin{array}{l}\text { Gastos en medidas } \\
\text { de protección }\end{array}$ & $48,903,718,332.00$ & $43,279,790,724.00$ & $26,948.28$ \\
\hline $\begin{array}{l}\text { Pérdidas por el co- } \\
\text { mercio informal }\end{array}$ & n.d. & n.d. & n.d. \\
\hline \multirow[t]{2}{*}{ Total } & n.d. & n.d. & n.d. \\
\hline & \multicolumn{3}{|c|}{ Cambio 2011-2013: } \\
\hline $\begin{array}{l}\text { Pérdidas económi- } \\
\text { cas directas }\end{array}$ & $-9.5 \%$ & $-17.0 \%$ & $-9.6 \%$ \\
\hline $\begin{array}{l}\text { Gastos en medidas } \\
\text { de protección }\end{array}$ & $2.6 \%$ & $-5.8 \%$ & $-6.9 \%$ \\
\hline
\end{tabular}

Fuente: cálculos propios con base en la Encuesta Nacional de Victimización de Empresas (Inegi 2012 y 2014).

*El valor real se refiere a pesos de 2010 ** Los promedios varían porque el número de empresas victimizadas, de empresas que reportaron haber suspendido acciones, de empresas que gastaron en medidas de protección y de empresas con pérdidas provocadas por el comercio informal fue variable. Por este motivo no se ofrece un promedio total de pérdidas.

Hay una clara geografía de la pérdida económica a razón del delito y estos promedios estatales se correlacionan en el tiempo. No obstante, no hay una correlación temporal entre las pérdidas en 2011 y 2013 en el ámbito de los estados. ${ }^{12}$ Las pérdidas promedio en 2011 no se asocian estadísticamente con las pérdidas promedio por empresa en 2013.

\footnotetext{
${ }^{12} \mathrm{r}$ lineal de Pearson $=0.091, \mathrm{p}=0.620$.
} 


\section{Cuadro 4}

\section{Promedio de pérdidas económicas a consecuencia del delito por} estado, 2011 y 2013*

\begin{tabular}{|c|c|c|c|}
\hline & 2011 & 2013 & Cambio \% \\
\hline Estados Unidos Mexicanos & 46,876 & 42,372 & -9.6 \\
\hline Aguascalientes & 25,249 & 32,662 & 29.4 \\
\hline Baja California & 48,556 & 44,180 & -9.0 \\
\hline Baja California Sur & 37,077 & 25,651 & -30.8 \\
\hline Campeche & 60,694 & 19,462 & -67.9 \\
\hline Chiapas & 41,937 & 23,128 & -44.9 \\
\hline Chihuahua & 51,148 & 38,402 & -24.9 \\
\hline Coahuila de Zaragoza & 36,965 & 28,126 & -23.9 \\
\hline Colima & 91,817 & 35,120 & -61.7 \\
\hline Ciudad de México & 32,825 & 64,451 & 96.3 \\
\hline Durango & 52,317 & 26,326 & -49.7 \\
\hline Guanajuato & 30,544 & 38,346 & 25.5 \\
\hline Guerrero & 49,284 & 49,899 & 1.2 \\
\hline Hidalgo & 61,101 & 16,446 & -73.1 \\
\hline Jalisco & 35,301 & 23,253 & -34.1 \\
\hline Estado de México & 25,323 & 42,022 & 65.9 \\
\hline Michoacán & 40,775 & 34,647 & -15.0 \\
\hline Morelos & 188,021 & 43,392 & -76.9 \\
\hline Nayarit & 14,021 & 29,582 & 111.0 \\
\hline Nuevo León & 81,231 & 49,152 & -39.5 \\
\hline Oaxaca & 40,439 & 30,817 & -23.8 \\
\hline Puebla & 41,575 & 27,246 & -34.5 \\
\hline Querétaro & 97,501 & 46,150 & -52.7 \\
\hline Quintana Roo & 31,883 & 17,240 & -45.9 \\
\hline San Luis Potosí & 46,058 & 93,233 & 102.4 \\
\hline Sinaloa & 56,766 & 30,244 & -46.7 \\
\hline Sonora & 42,334 & 90,790 & 114.5 \\
\hline Tabasco & 37,816 & 51,782 & 36.9 \\
\hline Tamaulipas & 91,708 & 43,331 & -52.8 \\
\hline Tlaxcala & 30,565 & 50,527 & 65.3 \\
\hline Veracruz & 65,851 & 73,624 & 11.8 \\
\hline Yucatán & 19,217 & 32,233 & 67.7 \\
\hline Zacatecas & 50,627 & 29,300 & -42.1 \\
\hline
\end{tabular}

Fuente: cálculos propios con base en la Encuesta Nacional de Victimización de Empresas (Inegi 2012 y 2014). *En valores reales o pesos de 2010. 
Otro hallazgo geográfico es la nula evidencia estadística de un patrón espacial en las pérdidas económicas a consecuencia del delito en el ámbito de los estados, con la única excepción del cambio 2011 a 2013 (gráfica 2). Con base en un análisis de autocorrelación espacial, se pudo detectar un patrón estadísticamente significativo de dispersión espacial en el cambio bienal, lo cual es un hallazgo atípico en geografía humana (cuadro 5). Este patrón de dispersión espacial se refiere a un patrón geográfico en donde estados con incrementos (promedio) en las pérdidas ocasionadas por el delito son contiguos a otros estados con decrementos (promedio) en las

\section{Mapa 2}

Mapas de las pérdidas económicas promedio a consecuencia del delito, 2011 y 2013

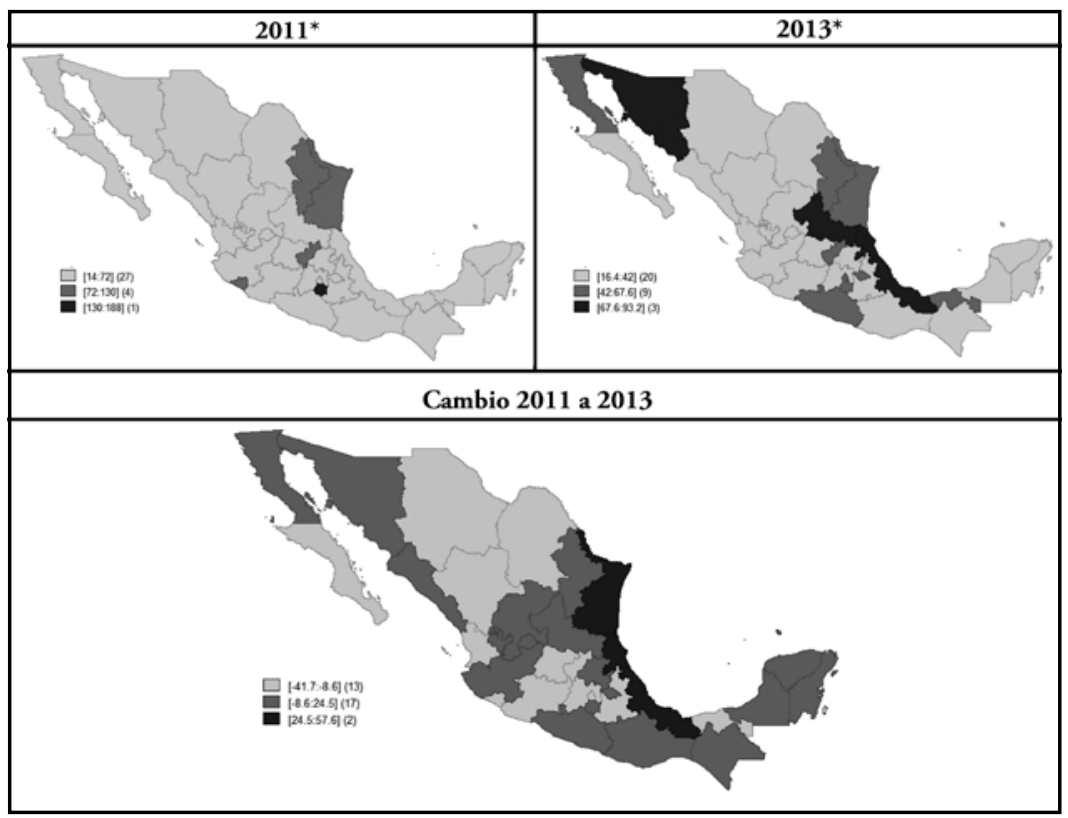

Fuente: cálculos propios con base en la Encuesta Nacional de Victimización de Empresas (Inegi, 2012 y 2014).

*En miles de pesos. Los intervalos son de longitud diferente en cada mapa, puesto que son sujetos a los datos de cada muestra; en todo caso, se siguió la regla de 3 intervalos del mismo tamańo cada año. 


\section{Cuadro 5}

Coeficientes de autocorrelación espacial de las pérdidas económicas a consecuencia del delito en el ámbito de los estados, 2011 y 2013

\begin{tabular}{lccl}
\hline & 2011 & 2013 & \multicolumn{1}{c}{ Cambio \% } \\
\hline Coeficiente I de Morán & -0.139 & 0.038 & $-0.309^{* * *}$ \\
\hline
\end{tabular}

Fuente: cálculos propios con base en la Encuesta Nacional de Victimización de Empresas (Inegi 2012 y 2014).

${ }^{*} \mathrm{p}<.10,{ }^{* *} \mathrm{p}<.05,{ }^{* * *} \mathrm{p}<.01$. Notas: son coeficientes globales I de Moran, calculados con una matriz de vecinos Reina de primer orden o por estricta contigüidad espacial.

pérdidas y viceversa. ${ }^{13}$ Este tipo de patrones geográficos son sumamente raros en la geografía. ${ }^{14}$

Hipotéticamente, este patrón de dispersión espacial puede deberse a un efecto de difusión contagiosa de la actividad criminal, en donde estados que vieron incrementarse sus promedios de pérdidas empresariales en el periodo, recibieron el impacto de las reducciones en las pérdidas en los estados vecinos a razón de un desplazamiento contagioso (como función de la contigüidad geográfica) de la actividad criminal. Una forma de probar de manera inicial esta hipótesis de difusión contagiosa del crimen entre estados, es a través del cálculo del coeficiente bivariado de autocorrelación espacial. El contagio espacial es el proceso por medio del cual hay una difusión de un fenómeno de un lugar a otro. Esto implica unir a la dimensión espacial con la dimensión temporal. No obstante, en este caso no se encuentra evidencia estadísticamente significativa de un proceso de difusión contagiosa en las pérdidas en un estado en 2013 con las pérdidas en los estados vecinos en 2011 (gráfica 1). Aunque el coeficiente es positivo y sugerente de tal proceso de difusión contagiosa, el coeficiente no alcanza significancia estadística $(\mathrm{I}=0.188, \mathrm{p}=0.301) .{ }^{15}$

Por otro lado, sin considerar la vecindad geográfica de los estados sino la dinámica interna de cada estado por sí mismo, se detecta una correlación negativa fuerte entre las pérdidas promedio en 2011 y el cambio en las pérdidas entre 2011 y 2013. Esto significa que los estados que tenían los mayores niveles de pérdidas económicas a consecuencia del delito en 2011 fueron los que experimentaron (por sí mismos y sin considerar una relación geográfica con sus estados vecinos) una mayor reducción proporcio-

${ }^{13}$ La dispersión espacial se puede representar de forma simple pensando en un tablero de ajedrez, en donde cuadros blancos son vecinos de otros negros y viceversa, o bien, que hay un intercalado de colores posibles que se halla perfectamente "disperso" a todo lo largo del tablero.

${ }^{14}$ Una excepción son las franquicias comerciales en una marca en donde sus establecimientos son localizados de forma separada y a una distancia óptima entre ellos (ni concentrada ni distribuidos de forma aleatoria) a fin de que cada uno posea un mercado exclusivo y no compitan entre ellos.

${ }^{15}$ Lo cual es función, en muchas ocasiones, del tamaño de la muestra. 


\section{Gráfica 1}

Coeficiente de autocorrelación espacial bivariada y diagrama de dispersión de los niveles de pérdidas económicas a consecuencia del delito, 2011 y 2013

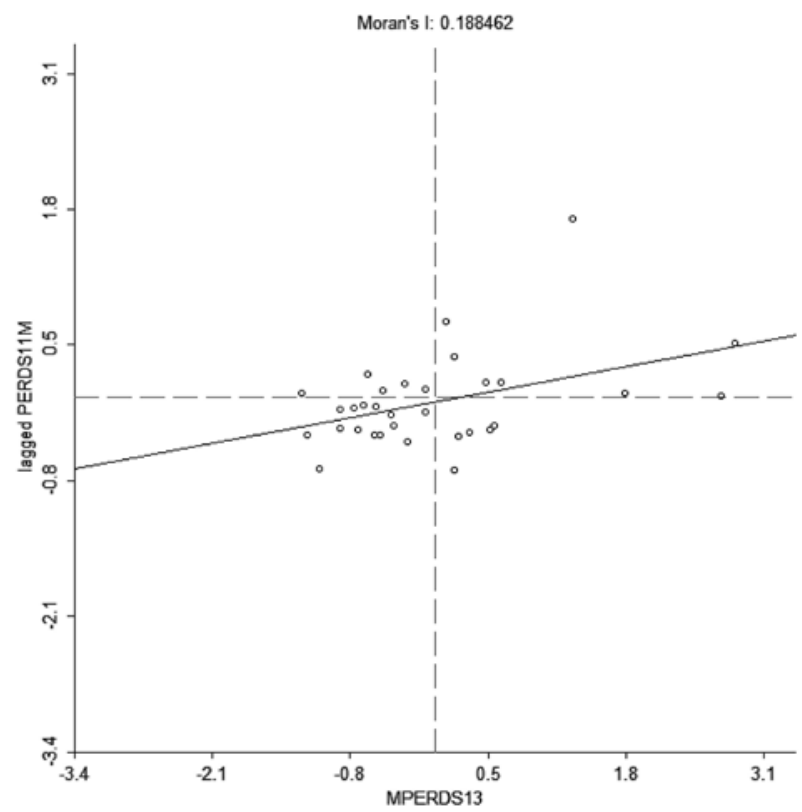

Fuente: cálculos propios con base en la Encuesta Nacional de Victimización de Empresas (Inegi, 2012 y 2014).

nal en tales pérdidas entre 2011 y $2013 .{ }^{16}$ Las mayores reducciones porcentuales en las pérdidas se presentaron en los estados que decremento en ganancias tenían previamente, mientras que los estados con los menores cambios fueron los que menos pérdidas tenían previamente; y los que estaban mejor fueron los que menos mejoraron en este indicador.

Con respecto al análisis de otro tipo de afectación o daño contra las empresas, se refiere el caso del gasto que se dedica a la adopción de medidas de protección contra el delito, las cuales pueden ser de tipos muy variados y no son exclusivas entre ellas, por ejemplo, la colocación de cerraduras o candados pueden hacerse en combinación con cambios en puertas o ventanas, o con la instalación de alarmas o videocámaras de vigilancia, rejas o bardas, contratación de vigilancia o seguridad privada, entre otras.

\footnotetext{
${ }^{16} \mathrm{r}$ lineal de pearson: $-0.542, \mathrm{p}=0.001$.
} 
Entre 2011 y 2013, el gasto promedio en este tipo de medidas se redujo de casi 29,000 pesos a casi 27,000 pesos. Esto sucedió porque efectivamente en 2013 menos empresas realizaron cambios o tomaron precauciones con respecto a 2011. El cuadro 6 muestra que, en básicamente todas las medidas de protección consideradas en la encuesta, hubo una reducción proporcional en el número de empresas que recurrieron a ellas. No obstante, nótese que siguen siendo muchas las empresas que toman alguna medida de protección contra el delito. Especialmente, el cambio o colocación de cerraduras es la medida más utilizada por las empresas: casi una de cada tres lo hace cada año.

Esta es la medida más utilizada porque es la más económica, las más lógica y generalizable a todas las empresas independientemente de su sector económico y horas de operación. Las medidas menos utilizadas son la contratación de vigilancia privada, la contratación de seguros y la instalación de sistemas de seguridad cibernéticos. Lo anterior es lógico, considerando que la contratación de vigilancia privada es muy onerosa y no accesible para la mayor parte de las empresas del país. Por otro lado, los seguros son instrumentos muy poco recurridos en general, salvo los legalmente indispensables para la operación de los negocios, y sólo una minoría de las empresas podrían ser afectados por algún delito cibernético.

\section{Cuadro 6}

Medidas de protección más frecuentes contra el delito, 2011 y 2013

\begin{tabular}{lrrr}
\hline & \multicolumn{1}{c}{2011} & \multicolumn{1}{c}{2013} & Cambio \\
\hline Total de empresas & $3,717,291$ & $3,793,806$ & 76,515 \\
$\begin{array}{l}\text { Que tomaron alguna medida de pro- } \\
\text { tección:* }\end{array}$ & $42.7 \%$ & $42.3 \%$ & $-0.4 \%$ \\
Cambió o colocó cerraduras o candados & $30.7 \%$ & $29.9 \%$ & $-0.7 \%$ \\
Cambió puertas o ventanas & $14.5 \%$ & $13.1 \%$ & $-1.4 \%$ \\
$\begin{array}{l}\text { Instaló alarmas o videocámaras de vigi- } \\
\text { lancia }\end{array}$ & $12.5 \%$ & $12.4 \%$ & $-0.1 \%$ \\
Colocó rejas o bardas & $11.6 \%$ & $11.2 \%$ & $-0.4 \%$ \\
Contrató vigilancia o seguridad privada & $5.1 \%$ & $4.9 \%$ & $-0.1 \%$ \\
Contrató seguros & $4.5 \%$ & $3.7 \%$ & $-0.8 \%$ \\
Instaló sistemas contra ataques ciber- & $2.5 \%$ & $2.1 \%$ & $-0.4 \%$ \\
néticos & & & \\
\hline
\end{tabular}

Fuentes: cálculos propios con base en la Encuesta Nacional de Victimización de Empresas (Inegi 2012 y 2014)

* Las empresas pueden haber adoptado dos o más medidas de protección. 
Cabe aclarar que éstas son medidas que se adaptaron solamente durante esos dos años, lo que no significa que más de millón y medio de empresas que contaban con alguna medida de protección contra el delito en 2013 estuvieran desprotegidas en 2011, ni que el restante dos millones de empresas también estuvieran desprotegidas.

Hay una clara geografía de la protección contra el delito en términos del gasto promedio dirigido a la adquisición de medidas de protección. Hay estados que sistemáticamente gastan más en promedio al respecto. Las empresas establecidas en los estados de Querétaro, Nuevo León. Morelos y la Ciudad de México son las que más han gastado en promedio estos dos años (cuadro 7). A la inversa, las empresas establecidas en Tlaxcala y Zacatecas son las que menos gasto en promedio han destinado para estos efectos.

Las empresas en la Ciudad de México incrementaron su gasto en protección $133 \%$ en estos dos años. De manera similar, las empresas que operan en Tabasco incrementaron su gasto en medidas de protección $123 \%$. Pero otros estados lo redujeron muy por encima del promedio nacional, tales como las empresas de Morelos, Nayarit, Sinaloa y Michoacán.

A diferencia de la nula correlación entre las pérdidas económicas estatales entre 2011 y 2013, el gasto empresarial en prevención contra el delito sí se correlaciona en el tiempo: los estados que más gastaban en 2011, también gastaban más en 2013. ${ }^{17}$ Del mismo modo, el gasto en 2011 se relaciona con el cambio entre 2011 y 2013, pero en este caso de forma negativa, es decir, los estados que más gastaban en 2011 fueron los que también más redujeron su gasto (aunque ya gastaran mucho) en el periodo. ${ }^{18}$

Como podría suponerse, los cambios en los promedios estatales de las pérdidas económicas ocasionadas por el delito, y los gastos correspondientes en medidas de protección contra el delito, se correlacionan positiva y fuertemente en el periodo (gráfica 2). ${ }^{19}$ Si bien la relación causal entre ambas variables de cambio es difícil de entrever en el ámbito agregado del estado, lo más intuitivamente lógico es que en los estados en donde más aumentaron las pérdidas también aumentaron más los gastos en prevención del delito a razón de lo primero y no al revés. Es decir, es lógico pensar que los gastos dirigidos a protegerse del delito se realizan en función de las pérdidas ocasionadas por el delito y no que las pérdidas económicasmotivan el gasto en protección.

En este sentido, los gastos en protección deben teóricamente reducir la probabilidad de victimización. De hecho, el análisis previo mostró que

\footnotetext{
${ }^{17} \mathrm{r}$ lineal de Pearson: $0.363, \mathrm{p}=0.041$.

${ }^{18} \mathrm{r}$ lineal de Pearson: $-0.469, \mathrm{p}=0.007$.

${ }^{19} \mathrm{r}$ lineal de Pearson: $0.455, \mathrm{p}=0.009$.
} 
Cuadro 7

Promedio de gastos en medidas de protección contra el delito por estado, 2011 y 2013*

\begin{tabular}{|c|c|c|c|}
\hline & 2011 & 2013 & Cambio \% \\
\hline Estados Unidos Mexicanos & 28,956 & 26,948 & -6.9 \\
\hline Aguascalientes & 16,404 & 18,241 & 11.2 \\
\hline Baja California & 39,672 & 23,642 & -40.4 \\
\hline Baja California Sur & 30,252 & 34,692 & 14.7 \\
\hline Campeche & 22,104 & 18,572 & -16.0 \\
\hline Chiapas & 13,849 & 19,993 & 44.4 \\
\hline Chihuahua & 43,567 & 27,871 & -36.0 \\
\hline Coahuila & 21,005 & 21,168 & 0.8 \\
\hline Colima & 29,223 & 15,912 & -45.5 \\
\hline Ciudad de México & 23,936 & 55,808 & 133.2 \\
\hline Durango & 19,633 & 14,110 & -28.1 \\
\hline Guanajuato & 20,295 & 19,469 & -4.1 \\
\hline Guerrero & 18,348 & 14,492 & -21.0 \\
\hline Hidalgo & 42,724 & 30,665 & -28.2 \\
\hline Jalisco & 27,764 & 19,493 & -29.8 \\
\hline Estado de México & 26,142 & 31,809 & 21.7 \\
\hline Michoacán & 32,027 & 14,451 & -54.9 \\
\hline Morelos & 62,293 & 18,269 & -70.7 \\
\hline Nayarit & 29,572 & 10,899 & -63.1 \\
\hline Nuevo León & 66,312 & 35,575 & -46.4 \\
\hline Oaxaca & 22,486 & 18,614 & -17.2 \\
\hline Puebla & 30,000 & 22,237 & -25.9 \\
\hline Querétaro & 55,633 & 67,608 & 21.5 \\
\hline Quintana Roo & 32,707 & 25,221 & -22.9 \\
\hline San Luis Potosí & 24,816 & 24,094 & -2.9 \\
\hline Sinaloa & 39,504 & 17,963 & -54.5 \\
\hline Sonora & 16,251 & 28,719 & 76.7 \\
\hline Tabasco & 16,469 & 36,840 & 123.7 \\
\hline Tamaulipas & 30,502 & 25,637 & -15.9 \\
\hline Tlaxcala & 12,018 & 13,858 & 15.3 \\
\hline Veracruz & 15,742 & 26,414 & 67.8 \\
\hline Yucatán & 25,759 & 15,851 & -38.5 \\
\hline Zacatecas & 17,228 & 11,585 & -32.8 \\
\hline
\end{tabular}

Fuentes: cálculos propios con base en la Encuesta Nacional de Victimización de Empresas (Inegi/ ENVE, 2012 y 2014). *En valores reales o pesos de 2010. Nota: Las empresas pueden haber adoptado dos o más medidas de protección. 


\section{Gráfica 2}

Diagrama de dispersión en el cambio en el promedio de pérdidas y el promedio de gasto en protección entre 2011 y 2013*

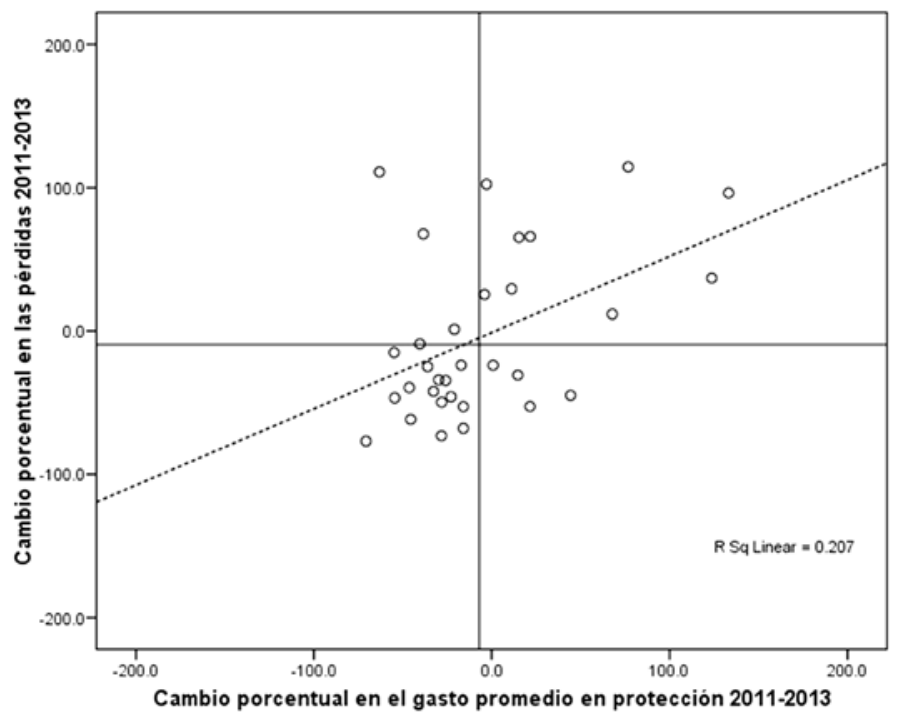

Fuentes: cálculos propios con base en la Encuesta Nacional de Victimización de Empresas (Inegi/ ENVE, 2012 y 2014). *Nota: las líneas vertical y horizontal se trazaron sobre los promedios nacionales de cambio.

el cambio en el gasto estatal en medidas de protección no se correlaciona de manera independiente con los niveles de prevalencia delictiva en 2013 ni con su cambio entre 2011 y 2013. En contraste, la concentración delictiva o promedio de delitos por empresa en el ámbito de los estados en 2013, sí se correlacionó negativamente con el cambio en el gasto promedio de los dos años anteriores, es decir, que en aquellos estados en donde más aumentó el gasto en protección contra el delito entre 2011 y 2013, también hubo un menor promedio de delitos por empresa en 2013 (gráfica 3). 


\section{Gráfica 3 \\ Diagrama de dispersión en el cambio promedio de gasto en protección entre 2011 y 2013 y la concentración delictiva en 2013*}



Fuentes: cálculos propios con base en la Encuesta Nacional de Victimización de Empresas, Inegi 2012 y 2014 . *Nota: la línea vertical se trazó sobre el promedio nacional de cambio en el gasto en protección y la horizontal sobre el promedio nacional de víctimas por empresa.

\section{Los correlativos estatales de las pérdidas económicas y el gasto en protección contra el delito}

Vistas las relaciones anteriores entre las pérdidas económicas y los gastos en protección relacionados con el delito contra las empresas, en esta sección se pone a prueba un modelo teórico victimológico para conocer los correlativos estadísticos de tales pérdidas y gastos. La pregunta básica que se trata de responder en esta sección es si los factores constitutivos de las teorías de la actividad rutinaria y lugares peligrosos se relacionan, más allá del margen de error, con los niveles de pérdidas y gasto relacionados con el delito en el ámbito de los estados. ${ }^{20}$ Se asume que un mayor nivel de oportunidad criminal, como lo formulan ambas teorías, se relaciona con un mayor nivel de pérdida y de gasto dirigido a protegerse.

Las dos teorías previas se pueden operacionalizar a través de cinco correlativos (Vilalta, 2017). Estos son: empresas disponibles $\left(\mathrm{x}_{1}\right)$, población joven $\left(\mathrm{x}_{2}\right)$, gasto en vigilancia $\left(\mathrm{x}_{3}\right)$, grado de urbanización $\left(\mathrm{x}_{4}\right)$, y divorcia-

\footnotetext{
${ }^{20}$ Para una explicación de estas teorías véase el estudio de Vilalta (2017).
} 
lidad $\left(\mathrm{x}_{5}\right) .{ }^{21}$ En este caso, visto que el gasto en vigilancia es una variable dependiente, se utiliza otra variable relacionada con la vigilancia también, y que es la percepción del empresariado al respecto de la disposición de ayuda por parte de las policías municipales. Aquí la expectativa teórica es que se esperaría que una peor percepción de los empresarios al respecto de la disposición a ayudar por parte de sus policías municipales, resultara en un mayor gasto en medidas de protección de la misma empresa contra el delito. Es decir, que habría una sustitución de seguridad pública por seguridad privada por parte de las mismas empresas. Ya se vio en una sección previa que el gasto promedio en protección en contra del delito aumentó ligeramente entre 2011 y 2013. En esta prueba del modelo teórico, las variables dependientes son los promedios estatales de pérdidas económicas $\left(\mathrm{y}_{1}\right)$ y gasto en medidas de protección contra el delito $\left(\mathrm{y}_{2}\right)$ en 2011 y 2013 , y los cambios porcentuales en las mismas variables $\left(\mathrm{y}_{3}\right)$ en el bienio.

Aunado a lo anterior, se agrega otro correlativo sobre la percepción que tienen los empresarios al respecto de la disposición que tienen las policías municipales a ayudar $\left(\mathrm{x}_{6}\right)$. En este caso, el correlativo se deduce del cambio porcentual estatal entre 2011 y 2013 de los empresarios que sí perciben una disposición a ayudar. Este es un correlativo no mencionado por las teorías anteriores, pero que se considera de importancia en el contexto mexicano, dados los bajos niveles de confianza en las autoridades policiales. Aquí, evidentemente, se esperaría una correlación negativa entre esta variable con el gasto promedio. Por otro lado, se agregan como controles los cambios bianuales en los niveles de prevalencia $\left(\mathrm{x}_{7}\right) \mathrm{y}$ de concentración $\left(\mathrm{x}_{8}\right)$ delictivas contra los hogares, a la vez y en la misma ecuación. La lógica de la inclusión de estos dos controles estadísticos es que el cambio en la distribución de la victimización en los hogares, medido por su prevalencia y concentración, puede tener un efecto hipotético independiente de los correlativos teóricos de oportunidad criminal, tanto en los niveles de pérdidas económicas como de gasto contra el delito por parte de las empresas.

Puesto que se detectó en un estudio previo que la relación en los cambios en los niveles de prevalencia delictiva entre los hogares y las empresas fue concomitante entre 2011 y 2013 (Vilalta, 2017), se requiere, por ende, controlar la covariación en los cambios estatales de la distribución de la victimización en los hogares por los dos conductos, la proporción de hogares víctimas (prevalencia) y el número de delitos por víctima en los hogares (concentración). Este control se realiza en la prueba integrada. El cuadro 8 muestra las estadísticas descriptivas (media y desviación estándar) de las variables dependientes, los correlativos teóricos y las variables de control.

\footnotetext{
${ }^{21}$ Se utilizan regresiones lineales de mínimos cuadrados.
} 


\section{Cuadro 8}

Estadística descriptiva*

\begin{tabular}{lrr}
\hline & $\begin{array}{c}\text { Media } \\
\text { aritmética }\end{array}$ & $\begin{array}{c}\text { Desviación } \\
\text { estándar }\end{array}$ \\
\hline Pérdidas económicas (2013) & 40,024 & 18,825 \\
Gastos en medidas de protección (2013) & 24,368 & 12,107 \\
Cambio en las pérdidas económicas (2011-2013) & $-3.8 \%$ & $57.8 \%$ \\
Cambio en los gastos en medidas de protección (2011-2013) & $-5.1 \%$ & $49.4 \%$ \\
Cambio en las empresas víctimas disponibles (2011-2013) & $2.1 \%$ & $0.6 \%$ \\
Cambio en la población 15 a 29 (2011-2013) & $0.5 \%$ & $1.9 \%$ \\
Cambio en el gasto en protección (2011-2013) & $3.4 \%$ & $53.9 \%$ \\
Cambio en la percepción de disposición de ayuda policial & $3.6 \%$ & $13.6 \%$ \\
(2011-2013) & $1.1 \%$ & $1.5 \%$ \\
Cambio en el crecimiento urbano (2011-2013) & $-5.6 \%$ & $7.7 \%$ \\
Cambio en la divorcialidad con hijos (2011-2013) & $8.7 \%$ & $20.6 \%$ \\
Cambio en la prevalencia victimológica contra los hogares & & \\
(2011-2013) & $9.1 \%$ & $15.5 \%$ \\
Cambio en la concentración victimológica contra los hogares & & \\
\hline
\end{tabular}

Fuente: elaboración propia ${ }^{*} \mathrm{~N}=32$.

El modelo teórico también se prueba dinámicamente, es decir, interesa probar si los cambios entre 2011 y 2013 en los correlativos teóricos se relacionan con los niveles de pérdidas y gastos en 2011 y sus cambios entre 2011 y 2013. Igualmente, se decidió utilizar la técnica de regresión de mínimos cuadrados ordinarios y se procedió ordenadamente en la prueba de las dos teorías, primero cada una a la vez y la integración de las dos al final.

En síntesis, los hallazgos de la prueba integrada del modelo son los siguientes (cuadro 9):

- Los estados que más incrementaron su gasto promedio en medidas de protección contra el delito entre 2011 y 2013, sufrieron las pérdidas económicas promedio derivadas del delito más elevadas en 2013.

- Los estados que más incrementaron su gasto promedio en medidas de protección contra el delito entre 2011 y 2013, también vieron sus pérdidas promedio incrementarse en el mismo periodo de dos años.

- Finalmente, los estados que vieron su población joven incrementarse más proporcionalmente, también tuvieron los mayores de- 


\section{Cuadro 9}

\section{Resultados de la regresión lineal en los niveles de pérdidas económicas y gastos en medidas de protección}

\begin{tabular}{|c|c|c|c|}
\hline & $\begin{array}{l}\text { Actividades } \\
\text { rutinarias }\end{array}$ & $\begin{array}{c}\text { Lugares } \\
\text { peligrosos }\end{array}$ & $\begin{array}{l}\text { Integración } \\
\text { teórica }\end{array}$ \\
\hline & \multicolumn{3}{|c|}{ Pérdidas económicas (2013): } \\
\hline Empresas víctimas disponibles (11-13) & 0.091 & - & -0.027 \\
\hline Población 15 a 29 (11-13) & -0.029 & - & 0.028 \\
\hline Gasto en protección (11-13) & $0.494^{* * *}$ & - & $0.574^{* * *}$ \\
\hline Crecimiento urbano (11-13) & - & -0.137 & -0.177 \\
\hline Divorcialidad con hijos (11-13) & - & -0.009 & -0.075 \\
\hline Cambio en la prev. vict. hogares (11-13) & - & - & -0.239 \\
\hline $\begin{array}{l}\text { Cambio en la conc. vict. hogares (11- } \\
\text { 13) }\end{array}$ & - & - & 0.234 \\
\hline Empresas en sector comercio (09) & & & -0.200 \\
\hline \multirow[t]{2}{*}{$\mathrm{R} 2$} & 0.252 & 0.019 & 0.373 \\
\hline & \multicolumn{3}{|c|}{ Gastos en medidas de protección (2013): } \\
\hline Empresas víctimas disponibles (11-13) & 0.197 & - & 0.229 \\
\hline Población 15 a 29 (11-13) & -0.232 & - & -0.234 \\
\hline Percepción de disposición policial & 0.117 & - & 0.069 \\
\hline Crecimiento urbano (11-13) & - & -0.174 & -0.096 \\
\hline Divorcialidad con hijos (11-13) & - & 0.199 & 0.220 \\
\hline Cambio en la prev. vict. hogares (11-13) & - & - & -0.168 \\
\hline $\begin{array}{l}\text { Cambio en la conc. vict. hogares (11- } \\
\text { 13) }\end{array}$ & - & - & 0.106 \\
\hline Empresas en sector comercio (09) & & & 0.191 \\
\hline \multirow[t]{2}{*}{$\mathrm{R} 2$} & 0.131 & 0.076 & 0.221 \\
\hline & \multicolumn{3}{|c|}{$\begin{array}{l}\text { Cambio en las pérdidas económicas } \\
\qquad(11-13)\end{array}$} \\
\hline Empresas víctimas disponibles (11-13) & 0.109 & - & -0.025 \\
\hline Población 15 a 29 (11-13) & 0.006 & - & 0.022 \\
\hline Gasto en protección (11-13) & $0.470^{* *}$ & - & $0.475^{* *}$ \\
\hline Crecimiento urbano (11-13) & - & 0.142 & 0.135 \\
\hline Divorcialidad con hijos (11-13) & - & 0.171 & 0.162 \\
\hline Cambio en la prev. vict. hogares (11-13) & - & - & -0.266 \\
\hline $\begin{array}{l}\text { Cambio en la conc. vict. hogares (11- } \\
\text { 13) }\end{array}$ & - & - & 0.309 \\
\hline Empresas en sector comercio (09) & & & -0.115 \\
\hline $\mathrm{R} 2$ & 0.219 & 0.045 & 0.325 \\
\hline
\end{tabular}


Cuadro 9 (continuación)

\begin{tabular}{|c|c|c|c|}
\hline & $\begin{array}{l}\text { Actividades } \\
\text { rutinarias }\end{array}$ & $\begin{array}{l}\text { Lugares } \\
\text { peligrosos }\end{array}$ & $\begin{array}{l}\text { Integración } \\
\text { teórica }\end{array}$ \\
\hline & \multicolumn{3}{|c|}{$\begin{array}{l}\text { Cambio en los gastos en medidas de protec- } \\
\text { ción }(11-13)\end{array}$} \\
\hline Empresas víctimas disponibles (11-13) & -0.095 & - & -0.060 \\
\hline Población 15 a 29 (11-13) & $-0.350^{*}$ & - & $-0.382^{*}$ \\
\hline Percepción de disposición policial & -0.004 & - & -0.040 \\
\hline Crecimiento urbano (11-13) & - & 0.088 & 0.101 \\
\hline Divorcialidad con hijos (11-13) & - & 0.135 & 0.197 \\
\hline Cambio en la prev. vict. hogares (11-13) & - & - & 0.094 \\
\hline $\begin{array}{l}\text { Cambio en la conc. vict. hogares (11- } \\
\text { 13) }\end{array}$ & - & - & -0.052 \\
\hline Empresas en sector comercio (09) & & & 0.109 \\
\hline $\mathrm{R} 2$ & 0.135 & 0.024 & 0.193 \\
\hline
\end{tabular}

${ }^{*} \mathrm{p}<.10,{ }^{* *} \mathrm{p}<.05,{ }^{* * *} \mathrm{p}<.01$. Notas: Todas las variables fueron normalizadas a través de puntuaciones $Z$ por lo que no hay diferencias entre coeficientes estandarizados y no estandarizados y la constante es igual a cero.

crementos en el gasto promedio en medidas de protección contra el delito.

La correlación positiva que se detectó entre los gastos en protección contra el delito y las pérdidas económicas provenientes del delito indica, con relativa claridad, que durante el bienio y en el ámbito agregado de los estados, los incrementos promedio que hicieron las empresas en los estados para protegerse del delito no fueron suficientes ni para reducir sus pérdidas económicas promedio en 2013 ni para reducir el incremento en estas pérdidas. Es decir, si bien efectivamente los gastos en medidas de protección y las pérdidas económicas en el nivel nacional se redujeron en promedio entre 2011 y 2013, aun así, los conjuntos estatales de empresas que más gasto dedicaron a su protección, no pudieron ni reducir sus niveles de pérdida por encima del promedio nacional, ni tampoco reducirlo por encima del promedio nacional. Lo que no se sabe es cuál habría sido la magnitud de las pérdidas económicas en estos estados si acaso las empresas en tales estados hubieran incrementado su gasto en medidas de protección; se podría especular que tal vez las pérdidas económicas provenientes del delito habrían sido aún mayores si no se hubieran aumentado los gastos en medidas de protección, pero esto constituye una hipótesis para probarse más adelante. 
Una correlación importante es la que se detecta sobre un incremento de la población joven con un decremento en el gasto promedio estatal en medidas dirigidas a protegerse del delito. En este caso, en los estados en donde más aumentó su población joven o entre 15 y 29 años, y por ende su vulnerabilidad delictiva según la teoría de las actividades rutinarias, a razón de que se predice según esta teoría mayores tasas de incidencia y prevalencia delictiva en zonas con mayores proporciones e incrementos de este segmento de la población, se encontró que fueron los mismos en donde los gastos empresariales promedio en protección tuvieron los mayores decrementos. Teóricamente, se esperaría que la relación fuera positiva, es decir, que en los estados en donde aumenta la población joven, las empresas radicadas ahí aumentaran el gasto en protección. Sin embargo, la relación que se detecta muestra precisamente lo contrario.

En este sentido, la prevalencia o proporción de empresas victimizadas en 2013 por estado se correlacionaba de forma independiente y positiva con los incrementos bianuales previos de su población joven. ${ }^{22}$ Es decir, aquellos estados en donde aumentó la población joven entre 2011 y 2013, también mostraron tener las mayores proporciones de empresas victimizadas durante 2013. Si relacionamos este hallazgo con el siguiente, aquel que se vincula con una correlación entre reducciones en el gasto en medidas de protección y aumentos en la población joven residente en el estado, lo que tenemos es que fue en aquellos estados en donde se redujo el gasto empresarial en protección y aumentó la población joven durante 2011 y 2013, es también en donde se registraron las mayores proporciones de empresas víctimas en 2013. Ésta es una cadena causal que tiene sentido lógico y que puede explicar las correlaciones detectadas al conectar intuitivamente las tres variables.

En otras palabras, los estados que en 2013 tuvieron las mayores proporciones de empresas victimizadas por el delito, fueron aquellos en donde se presentó una combinación de: $a$ ) un incremento de su población joven (la cual tiene una mayor proclividad a cometer delitos) y $b$ ) un decremento por parte de sus empresas en los gastos dirigidos a protegerse del delito. En síntesis: más criminales motivados y menos gasto en protección durante un periodo, lleva a mayores cifras de victimización contra las empresas al final de dicho lapso.

${ }^{22}$ Este cuadro no se muestra por razones de espacio. 


\section{Otros dańos provocados por el delito e ideas para siguientes estudios}

Además de las pérdidas económicas y los gastos dirigidos a la protección contra el delito, las empresas también son afectadas por la suspensión o cancelación de acciones o decisiones empresariales por motivos, nuevamente, relacionados con la victimización delictiva. En esta sección solamente se revisan las cifras de 2011 puesto que no se contabilizaron tales los dańos por dichos conceptos en 2013. No obstante, se consideran importantes y por ende se agrega esta sección aunque no se pueda analizar a través del tiempo.

Cuando en 2011 entre las preguntas formuladas por la ENVE se cuestionó a los empresarios sobre la cifra a la que ascenderían los daños o pérdidas económicas estimadas sobre la base de una idea de un retorno económico en el caso de no haber tenido que modificar sus operaciones o planes, los empresarios del país dieron una cifra total de 62 mil millones de pesos. ${ }^{23}$

Estos daños sucedieron por: a) cancelaciones en planes de inversión, b) reducciones en los horarios de producción o comercialización, c) modificaciones en las rutas de distribución -todo lo anterior a consecuencia de una victimización delictiva en los hechos- $\mathrm{y} d$ ) el comercio informal, el cual genera pérdidas en el sector formal empresarial. En este caso, los empresarios estiman que el comercio informal les generó afectaciones en sus ventas y producción por 39 mil millones de pesos.

En suma, el daño empresarial que ocasionó la delincuencia y la irregularidad, en sus diferentes formas de actuar, ascendió a los $217 \mathrm{mil}$ millones de pesos solamente en 2011. Esta es una cifra equivalente a $1.5 \%$ del PIB ese año. ${ }^{24}$ Es así que la delincuencia ocasiona enormes pérdidas materiales, costos en protección y otras pérdidas también en ganancias potenciales o esperadas. Cabe decir que esta cifra es menor a la que se reporta desde Estados Unidos de América, en donde se estima que el costo de la actividad criminal representa 11.9\% del PIB (Anderson, 1999), o en Italia, en donde se reporta que la afectación es de alrededor de $2.6 \%$ del PIB (Detotto y Vannini, 2013). Claro que estas cifras son sensibles a la metodología utilizada y las comparaciones deben hacerse con reservas. ${ }^{25}$

Además de los daños no económicos y las pérdidas económicas derivadas de la actividad delincuencial, las empresas sufren además de otros daños que

\footnotetext{
${ }^{23}$ Naturalmente se trata de una inferencia de una muestra de empresarios al total nacional.

${ }^{24}$ El PIB en 2011 equivalía a 14.5 millones de millones de pesos.

${ }^{25}$ Las estimaciones de costos y daños son realizadas con metodologías y niveles de información diferentes.
} 
constituyen afectaciones en los planes y operaciones de la empresa, y que estadísticamente la ENVE considera como "suspensión o cancelación de acciones". Es importante aclarar que la ENVE estima conceptualmente que el monto económico derivado de la suspensión o cancelación de acciones no debe sumarse a otros conceptos de daños cuantificables, es decir, no debe agregarse a la suma de las pérdidas económicas y de los costos de la inseguridad, sobre la premisa de que la suspensión o cancelación de acciones no implica necesariamente una pérdida de la totalidad de este monto, sino que, en algunos casos, la pérdida se puede ver reflejada únicamente en la tasa de retorno de inversión. Es decir, la cuantificación del daño por este conducto no deriva de un cálculo de una pérdida o gasto material, sino de una estimación inmaterial de una ganancia no lograda a consecuencia de la experiencia factual delictiva. Entre los posibles tipos de suspensión o cancelación de acciones se contabilizaron los siguientes (Inegi, 2012):

- Cancelar planes de crecimiento a su establecimiento (inversiones)

- Dejar de comercializar o hacer negocios con otras empresas

- Dejar de manejar efectivo en las instalaciones de su establecimiento

- Reducir los horarios de producción o comercialización de bienes o servicios

- Cancelar rutas de distribución o venta de productos

- Que el(los) dueño(s) dejaran de asistir al establecimiento

- Otras. ${ }^{26}$

Estas suspensiones o cancelaciones de acciones son decisiones reactivas contra el delito. En este sentido, se pueden visualizar dos tipos de reacciones empresariales contra la experiencia delictiva, por un lado, se decide dejar de hacer lo que se tenía planeado, con las respectivas pérdidas en oportunidades de negocios que esto representa, y por otro lado, se gasta en medidas de protección contra el delito, con los respectivos incrementos en los costos de operación de las empresas.

Pero siguiendo con el análisis de la reacción empresarial del tipo de una suspensión o cancelación de acciones, destacan dos hallazgos criminológicos y problemas empresariales a la vez muy notables. Primero, que en 2011 el monto estimado por los empresarios que resultó de la suspensión o cancelación de acciones por motivos de victimización criminal ascendió a los 62 mil millones de pesos. En la lectura de este dato téngase presente, que este tipo de daño se refiere a la pérdida en una tasa esperada de retorno por la realización de tales acciones. Es decir, se trata de una ganancia no lograda, o bien, visto al revés, de una pérdida en

${ }^{26}$ Como categoría residual típica en cualquier encuesta de hechos y opiniones. 


\section{Cuadro 10 \\ Empresas y pérdidas en el retorno de inversión a razón de la suspensión o cancelación de acciones a consecuencia del delito por gran sector de la economía, 2011}

\begin{tabular}{lcccc}
\hline & $\begin{array}{c}\text { Empresas } \\
\text { victimizadas* }\end{array}$ & $\begin{array}{c}\text { Que suspendieron o } \\
\text { cancelaron acciones }\end{array}$ & Porcentaje & $\begin{array}{c}\text { Promedio de } \\
\text { pérdidas }\end{array}$ \\
\hline $\begin{array}{l}\text { Estados Unidos } \\
\text { Mexicanos }\end{array}$ & $1,277,037$ & 425,758 & 33.3 & $147,652.3$ \\
Industria & 691,462 & 53,585 & 7.8 & $371,119.3$ \\
Comercio & 152,072 & 148,328 & 97.5 & $150,952.2$ \\
Servicios & 433,404 & 223,844 & 51.7 & $91,970.8$ \\
\hline
\end{tabular}

Fuente: cálculos propios con base en la Encuesta Nacional de Victimización de Empresas (Inegi, 2012). *Nota: no incluye las empresas victimizadas por actos de corrupción.

oportunidades de negocios, las cuales deben impactar, por un lado, en la productividad de las empresas, y por el otro, y eventualmente, en los precios al consumidor. Segundo, que básicamente todas $(97.5 \%)^{27}$ las empresas en el sector comercio suspendieron o cancelaron alguna actividad planeada a razón de una experiencia de victimización ese mismo año (cuadro 10). La reacción empresarial contra el delito es uniforme al interior de este sector.

Las pérdidas producidas por el sector informal son diferentes de los anteriores y merecen una descripción y análisis aparte. Es un daño particular porque se asocia a actividades cometidas por empresas no registradas en el Fisco, es decir, por una parte del ampliamente llamado sector informal de la economía. La forma en la que el sector informal empresarial genera pérdidas en el sector formal empresarial es a través del propiamente comercio informal o la venta de productos ilegales; lo cual puede ser constitutivo de delito. El comercio informal se define por la ENVE (Inegi/ENVE, 2012) como aquel realizado por puestos ambulantes no autorizados en los alrededores de los establecimientos formalmente autorizados, por la producción o venta de productos piratas, apócrifos o robados. Todo lo anterior son actividades empresariales ${ }^{28}$ ilegales, las cuales generan pérdidas en las empresas legalmente establecidas en dos vías: en sus ventas o en su producción.

\footnotetext{
${ }^{27}$ Hay que considerar el margen de error relativo de la encuesta aún en estas cifras y con el uso del factor de expansión.

${ }^{28}$ Bajo la consideración de que bajo una definición amplia pero más adecuada, por actividades empresariales se pueden entender todas aquellas dirigidas a la realización de actividades económicas, sean legales o ilegales.
} 
El número total de empresas legalmente establecidas que fueron afectadas en 2011 por el sector informal de la economía fue de 436,000 (cuadro 11). Hay, nuevamente, notables diferencias entre estados. Las mayores proporciones de empresas afectadas se hallan en la Ciudad de México y Morelos, con alrededor de una de cada cinco empresas directamente afectadas. Los sectores empresariales menos afectados son los que se ubican en los estados de Zacatecas, Tamaulipas y Coahuila.

\section{Cuadro 11}

Empresas afectadas por el sector informal por estado, 2011

\begin{tabular}{|c|c|c|c|}
\hline & Total de empresas & Empresas afectadas & Porcentaje \\
\hline Estados Unidos Mexicanos & $3,717,291$ & 436,241 & 11.7 \\
\hline Aguascalientes & 42,852 & 6718 & 15.7 \\
\hline Baja California & 84,888 & 12,891 & 15.2 \\
\hline Baja California Sur & 22,860 & 2480 & 10.8 \\
\hline Campeche & 27,774 & 2985 & 10.7 \\
\hline Chiapas & 125,260 & 22,359 & 17.9 \\
\hline Chihuahua & 90,210 & 5348 & 5.9 \\
\hline Coahuila & 83,750 & 4104 & 4.9 \\
\hline Colima & 26,844 & 2205 & 8.2 \\
\hline Ciudad de México & 380,618 & 101,161 & 26.6 \\
\hline Durango & 46,056 & 3480 & 7.6 \\
\hline Guanajuato & 185,642 & 27,861 & 15.0 \\
\hline Guerrero & 105,632 & 13,126 & 12.4 \\
\hline Hidalgo & 84,834 & 11,946 & 14.1 \\
\hline Jalisco & 270,661 & 20,600 & 7.6 \\
\hline México & 476,791 & 37,280 & 7.8 \\
\hline Michoacán & 171,450 & 18,341 & 10.7 \\
\hline Morelos & 78,992 & 16,096 & 20.4 \\
\hline Nayarit & 38,824 & 2402 & 6.2 \\
\hline Nuevo León & 135,698 & 9082 & 6.7 \\
\hline Oaxaca & 124,320 & 23,829 & 19.2 \\
\hline Puebla & 216,017 & 23,702 & 11.0 \\
\hline Querétaro & 58,190 & 9577 & 16.5 \\
\hline Quintana Roo & 41,683 & 2633 & 6.3 \\
\hline San Luis Potosí & 80,628 & 4930 & 6.1 \\
\hline Sinaloa & 79,860 & 4916 & 6.2 \\
\hline Sonora & 81,786 & 6800 & 8.3 \\
\hline Tabasco & 51,551 & 3827 & 7.4 \\
\hline
\end{tabular}


Cuadro 11 (continuación)

\begin{tabular}{lccc}
\hline & Total de empresas & Empresas afectadas & Porcentaje \\
\hline Tamaulipas & 106,677 & 4802 & 4.5 \\
Tlaxcala & 51,920 & 7873 & 15.2 \\
Veracruz & 223,148 & 14,174 & 6.4 \\
Yucatán & 72,818 & 6677 & 9.2 \\
Zacatecas & 49057 & 2034 & 4.1 \\
\hline
\end{tabular}

Fuente: cálculos propios con base en la Encuesta Nacional de Victimización de Empresas Inegi/ ENVE, (2012).

Ahora bien, cuál es la magnitud económica de las pérdidas y los grandes sectores de la economía más afectados por estas actividades informales, afectan al sector empresarial formal que está especialmente concentrado en el sector Comercio. El monto total de las pérdidas asciende a 39 mil millones de pesos, lo que da un promedio de 89,000 pesos por empresa afectada (cuadro 12). Este es un daño promedio mayor al que ocasiona la delincuencia. Es el sector comercio el que posee la mayor proporción de empresas afectadas por estas actividades comerciales realizadas en puestos ambulantes no autorizados en los alrededores de los establecimientos formalmente autorizados, en este caso, por la producción o venta de productos piratas, apócrifos orobados. Más de la mitad (57.4\%) de las pérdidas por este rubro se concentra en este sector. ${ }^{29}$

\section{Cuadro 12}

Empresas y pérdidas afectadas por el sector informal por gran sector de la economía, 2011

\begin{tabular}{lrrcr}
\hline & Empresas & Afectadas & Porcentaje & Promedio $^{*}$ \\
\hline Estados Unidos & $3,717,291$ & 436,241 & 11.7 & 89,499 \\
Mexicanos & & & & \\
Industria & 455,062 & 41,367 & 9.1 & 224,224 \\
Comercio & $1,761,889$ & 279,316 & 15.9 & 80,267 \\
Servicios & $1,500,241$ & 115,558 & 7.7 & 63,584 \\
\hline
\end{tabular}

Fuente: cálculos propios con base en la Encuesta Nacional de Victimización de Empresas (Inegi/ ENVE, 2012). *Nota: El promedio se calcula sobre la base de las empresas afectadas.

${ }^{29}$ Los 22 mil millones de pesos reportados en pérdidas en el sector del Comercio representan $57.4 \%$ del total de las pérdidas empresariales ocasionadas por el sector informal. 


\section{Discusión y conclusiones}

La descripción de los patrones geográficos y correlativos estatales de la victimización delictiva contra las empresas que se presenta en este artículo se centra solamente en dos conceptos y variables: las pérdidas económicas y los gastos en protección contra el delito. Se argumenta que el primer concepto es central para la toma de decisiones de localización empresarial, volumen de inversión y actividades lo cual, a su vez, genera costos para toda la sociedad por la vía de pérdida de empleo, productividad y oportunidades de desarrollo (Buvinic et al., 2005). El segundo elemento es un costo producto de los fallos en materia de seguridad pública. La seguridad privada tiene auge donde la seguridad pública falla.

Los hallazgos más reveladores son los siguientes: el número de empresas victimizadas fue de 336.3 por mil en 2013. Sólo ese año, el total de pérdidas económicas directas reportadas y que fueron ocasionadas por el delito contra las empresas, ascendió a los 65 billones de pesos. ${ }^{30}$ Los gastos en protección ascendieron a 45 billones de pesos ese mismo año. El delito más frecuente fue el robo/asalto de bienes o dinero. Los actos de corrupción vinieron en segundo lugar, y la extorsión en tercero. Las empresas más afectadas, en términos de pérdidas económicas promedio en 2013 fueron las localizadas en San Luis Potosí (93,000 pesos), Sonora (90,000 pesos) y Veracruz (73,000 pesos). Las empresas que más gastaron en mecanismos de protección contra el delito, de nuevo en promedio y sólo para 2013, fueron las que se localizan en los estados de Querétaro (67,000 pesos), Ciudad de México (55,000 pesos) y Tabasco (36,000pesos). Finalmente, el correlativo más fuertemente asociado a las pérdidas económicas en el ámbito de los estados fueron precisamente los gastos en protección y se debe notar que son las empresas localizadas en la Ciudad de México las que más reportan ser afectadas por el sector informal (26.6\%), en particular las que pertenecen al sector comercio.

Pese a que muchos estudios especializados se han concentrado en estudiar el daño que realiza el crimen organizado en las empresas (Williams y Godson, 2002; Tulyakov, 2001; Van Duyne, 1996 y 1993), en realidad queda demostrado en este estudio que la mayoría de los delitos cometidos contra los empresarios son en realidad obra de la delincuencia desorganizada (robo hormiga) y los funcionarios públicos (actos de corrupción). Por supuesto, no deben omitirse los delitos de extorsión, tercer tipo de delito más frecuente, que, por su naturaleza, son típicos de la delincuencia organizada.

\footnotetext{
${ }^{30}$ En pesos de 2010.
} 
Es importante en adelante complementar el análisis victimológico de las empresas en relación con sus determinantes individuales y contextuales, así como con sus soluciones de prevención. Este estudio aboga por incluir en elanálisis de la delincuencia y la violencia en el país, al sector empresarial, el cual es un actor central y muy poco estudiado en este rubro. Si una política basada en evidencias es lo que realmente se busca hacer en adelante, se debe empezar con el cálculo de la magnitud y el estudio de la distribución de este problema de la victimización delictiva.

\section{Fuentes consultadas}

Anderson, David A. (1999), "The aggregate burden of crime2", The Journal of Law and Economics, 42 (2), The University of Chicago, Chicago, Estados Unidos de América, pp. 611-642.

Buvinic, Mayra, Andrew Morrison y María Beatriz Orlando (2005), "Violencia, crimen y desarrollo social en América Latina y el Caribe", Papeles de población, 11 (43), Universidad Autónoma del Estado de México, Toluca, México, pp. 167-214.

Brand, Sam y Richard Price (2000), The economic and social cost of crime, Economics and Resource Analysus Research, Development and Statistics Directorate Home Office, Londres, Inglaterra.

Detotto, Claudio y Manuela Pulina Vaninni (2013), "Does more crime mean fewer jobs?" European Journal of Law and Economics, 36 (1), Springer International Publishing AG, New York, Estados Unidos de América, pp. 183-207.

Duyne, Petrus C. Van (1996), "Organized crime, corruption and power", Crime, Law and Social Change, 26 (3), Springer International Publishing AG, New York, Estados Unidos de América, pp. 201-238.

Duyne, Petrus C. Van (1993), "Organized crime and business crimeenterprises in the Netherlands", Crime, law and social change, 19 (2), Springer International Publishing AG, New York, Estados Unidos de América, pp. 103-142.

Inegi (Instituto Nacional de Geografía, Estadística e Informática) (2012), "Encuesta Nacional de Victimización de Empresas (ENVE)", Inegi, Aguascalientes, México, <http://www.inegi.org.mx/est/ 
contenidos/proyectos/encuestas/establecimientos/otras/enve/ enve2012/default.aspx>, 19 de octubre de 2016.

Inegi (Instituto Nacional de Geografía, Estadística e Informática) (2014), "Encuesta Nacional de Victimización de Empresas (ENVE)", Inegi, Aguascalientes, México, <http://www.inegi.org.mx/est/ contenidos/proyectos/encuestas/establecimientos/otras/ enve/2014/default.aspx>, 19 de octubre de 2016.

Inegi (Instituto Nacional de Geografía, Estadística e Informática) (2014), "Encuesta Nacional de Victimización y Percepción sobre Seguridad Pública (ENVIPE)”, Inegi, Aguascalientes, México, <http:// www.beta.inegi.org. mx/proyectos/enchogares/regulares/envipe/2014/>, 19 de octubre de 2016.

Tulyakov, Vyacheslav (2001), "The dualism of business victimization and organized crime", Trends in Organized Crime, 6 (3-4), Springer International Publishing AG, Nueva York, Estados Unidos de América, pp. 94-99.

Williams, Phil y Roy Godson (2002), "Anticipating organized and transnational crime", Crime, Law and Social Change, 37 (4), Springer International Publishing AG, New York, Estados Unidos de América, pp. 311-355.

Vilalta, Carlos (2017), La victimización de las empresas en México: conceptos, teorías y mediciones, Centro de Investigación y Docencia Económicas (CIDE), México, Ciudad de México (en prensa).

Recibido: 23 de septiembre de 2016. Aceptado: 9 de febrero de 2017. Corregido: 9 de abril de 2017.

Carlos Javier Vilalta-Perdomo. Doctor en estudios urbanos por Portland State University. Actualmente es profesor-investigador en la División de Administración Pública (DAP) del Centro de Investigación y Docencia Económicas (CIDE). Ha sido profesor visitante adjunto en el Departamento de Criminología y Justicia Criminal de la Universidad de Missouri en St. Louis (UMSL) e investigador visitante (en orden cronológico inverso) en las universidades de California en San Diego, Cambridge, McGill, 
Washington University en St. Louis, Houston y UNC-Chapel Hill. Es miembro del Sistema Nacional de Investigadores nivel III. Sus líneas de investigación son elementos espaciales y temporales del crimen y el miedo al crimen, las políticas de prevención, la estadística criminal y las poblaciones carcelarias. Entre sus últimas publicaciones se encuentran: “México. Capítulo 8", en Decker, Scotty Nerea Marteache (eds.), International handbook of juvenile justice, Springer International Publishing AG, Nueva York, Estados Unidos de América, pp. 115-134 (2016); "Crime and Justice in Latin America", en Beth M. Huebner (ed.), Oxford bibliographies in criminology, Oxford University Press, Nueva York, Estados Unidos de América, pp. 10 (2016); en coautoría: "Assessing the role of context on the relationship between adolescent marijuana use and property crimes in Mexico", Substance Use \& Misuse, 52 (2), Tylor and Francis, Londres, Reino Unido, pp. 152-163 (2017). 